\title{
Att använda biskopsvisitationsprotokoll som historisk källa
}

\author{
Av Olle Larsson, doktorand i historia
}

\author{
Länk till presentation av Olle Larsson
}

\section{Måns Haraldssons och Ingeborg Jonsdotters trassliga äktenskap.}

Den 13 juli 1652 visiterade växjöbiskopen Zacharias Lundebergius Malmbäcks församling. Där förhörde han sig bland annat om den vigsel som ägt rum mellan Måns Haraldsson och Ingeborg Jonsdotter några år tidigare. De var båda två närvarande vid visitationen och fick ge sina versioner av hur det hela hade gått till.

Måns och Ingeborg hade flera år tidigare tjänat som dräng och piga hos en man vid namn Jon. Under deras vistelse där hade Ingeborg besökt Måns nattetid. Till en början hade han inte befattat sig med henne men omsider blev frestelserna honom övermäktiga, och han hade då haft könsumgänge med henne. Detta hade hänt vid Larsmässotid och en tid härefter hade de vigts vid varandra. Hur denna vigsel gått till rådde det emellertid skilda uppfattningar om.

Måns berättade att han en tid efter deras umgänge begivit sig till en man vid namn Erik i Svenshult för att hämta några saker. Det var för övrigt i Svenshult som Måns och Ingrid haft umgänge med varandra. Då Måns kom hem till Erik, var en präst i hans sällskap. Denne, herr Lars, hade varit på besök hos Eriks sjuka grannfru för att ge henne sakramentet. Det var nu sent på kvällen. Prästen och Erik kände tydligen till Måns förbindelse med Ingeborg och försökte övertala honom att gifta sig med henne, eftersom även Ingeborg var närvarande. Herr Lars och Erik ville att de genast skulle vigas vid varandra i huset där de var, och prästen sa att han fått biskop Baazius tillstånd till denna förrättning. Måns vägrade och bad att först få tala med sina föräldrar. Detta förvägrades honom och i stället uppmanades han att frivilligt låta sig vigas vid Ingeborg. Då han fortfarande vägrade, lät Erik sända efter en töm att binda honom med, och han tog honom härefter i armen och ledde honom fram till Ingeborg. Prästen räckte fram en ring men Måns vägrade att ta emot den. Han svarade sedan nekande på frågan, om han ville ha Ingeborg till hustru. Trots hans protester genomfördes vigseln, och därefter sa prästen: " nu har jag vigt er, gå nu till biskopen och klaga"!

Detta var Måns version av hur det hela gått till. Prästen som vigt dem var också närvarande och påpekade ännu en gång att biskop Baazius givit honom tillstånd att förrätta vigseln. Det framkom att Måns och Ingegerd stannat kvar hos Erik på natten men att de inte legat tillsammans, det vill säga, i samma säng. Efter det att Måns berättat om det skedda var det dags för Ingeborg att ge sin version av vad som hänt.

Hon berättade att hon levt tillsammans med Måns i trefjärdedels år och att de under denna tid "gingo till duk och disk och levde väl tillsammans". Allt hade varit frid och fröjd så länge de levde i Ödestugu socken, men då de flyttade till Malmbäck förändrades Måns sinnelag. Detta intygades av flera av dem som var närvarande, och de berättade också att Ingeborg var en rättskaffens kvinna och att Måns inte hade något att beskylla henne för. Måns anklagade emmellertid henne för att ha mjölkat några kor som tillhörde en annan. Han beskyller alltså henne för trolldom. Denna anklagelse kunde han dock inte bevisa. Ingeborg berättade att det var han som begivit sig till henne på natten, och inte tvärt om som Måns påstått. Han hade då sagt: " ... hade jag varit hos er en gång så skulle jag väl 
sedan öfftare få er vilja". Ingegerd berättade också att man alls inte låtit skicka efter en töm vid vigseln. Herr Lars hade emellertid sagt: " om dom tog och band dig med en töm och slängde dig i fängelse så vore det din rätta lön ". Erik hade förvisso tagit Måns i armen vid vigseln, eftersom han inte stod tillräckligt nära bruden. Ingen hade heller hört honom svara något annat än ja på frågan om han ville gifta sig med henne.

När både Måns och Ingeborg avgivit sina berättelser, bestämde biskopen att avgörandet i frågan skulle uppskjutas en tid, så att de fick tid på sig att bli sams. Om de inte kunde förlikas och leva tillsammans, skulle saken tas upp till vidare behandling i domkapitlet.[1]

\section{Varför skulle biskopen visitera? - Biskopsvisitationernas regelverk.}

Måns och Ingeborgs oenighet om vad som egentligen hänt mellan dem var ett av alla de ärenden som togs upp till behandling på biskopsvisitationerna i Växjö stift under 1650talet. I det här fallet handlar det om två gifta människor som levde oroligt i sitt äktenskap, men även andra ärenden som t ex rörde kyrkans ekonomi, reparationer, löner och tjänstetillsättningar kunde tas upp till behandling liksom frågor rörande ordningen i församlingen, människornas katekeskunskaper, fylleri, slagsmål, stölder etc.[2]

Vad var då en biskopsvisitation? Vilket syfte hade den? Den biskop som visiterade i Växjö stift under 1650-talet hade i huvudsak två att förhålla sig till. Dessa var Kyrkoordningen 1571 och visitationsordningen Cursus Visitationis Dioecesis Wexionensis. Man bör hålla i minnet att detta var tiden innan de kyrkliga enhetssträvandena hade slagit igenom på allvar i Sverige. En egentlig riksgiltig kyrkolag saknades och den som fanns, dvs KO 1571, kompletterades av diverse stiftsstadgor runt om i Sverige. Cursus är att betrakta som en lokal stiftsstadga för Växjö stift även om forskningen har visat på denna stadgas stora betydelse för de bestämmelser kring biskopsvisitationerna som kom att kodifieras i och med antagandet av kyrkolagen 1686.

I både KO 1571 och Cursus stadgades det att biskopsvisitationer årligen skulle hållas i siften runt om i Sverige. Om biskoparna av någon anledning var förhindrade att genomföra någon visitationsresa, kunde de låta någon prost eller någon annan pålitlig man utföra visitationerna i deras ställe. Vikten av att visitationer genomfördes årligen poängteras i KO. Enligt regelverken var biskopsvisitationerna till för att biskopen skulle kunna sköta det som i samma förordningar angavs vara hans ämbetsplikter. Vid visitationerna skulle biskoparna först av allt kontrollera sitt underlydande prästerskap. Han skulle se till att de på rätt sätt förde ut Guds ord till församlingarna, delade ut sakramenten, undervisade sina församlingsbor och i allt väsentligt skötte sina prästerliga åligganden på ett korrekt och riktigt sätt. Det var inte bara prästerskapets ämbetsutövande som skulle undersökas, utan även deras leverne skulle kontrolleras. Om biskopen upptäckte att något inte stod rätt till, skulle den felande manas till bättring, och om detta inte hjälpte skulle den felande bestraffas.

Inte bara prästerskapet utan också församlingsbornas, menige mans, religiösa och moraliska leverne skulle undersökas. Biskopen skulle noga ge akt på att de höll sig till Guds rena ord, vördade sakramenten och bemödade sig om att lära sig sin katekes. Han skulle också kontrollera att ingen vantro eller vidskepelse fanns i församlingarna och även ge akt på hur föräldrarna uppfostrade sina barn. Vad det gäller församlingsbornas leverne skulle biskopen noga ha uppsikt över hur det stod till med sedligheten i församlingarna. Han skulle också undersöka om människor levde illa i sina äktenskap och allmänt kontrollera att det rådde ordning och reda i församlingarna. Om han upptäckte några brister, skulle dessa rättas till först och främst genom förmaningar, och om detta inte hjälpte genom bestraffning av den skyldige.

Det kan vara värt att påpeka att KO 1571 och Cursus i stort sett överensstämmer vad gäller biskopens uppgifter vid visitationerna. Cursus är dock mer utförlig beträffande katekesförhören och betonar katekeskunskaperna stora betydelse för människorna.[3] 
Biskopsvisitationerna var alltså ett sätt för biskoparna att kontrollera sitt underlydande prästerskap och deras församlingsbor. Visitationerna var emellertid inte enbart en kontrollinstans för biskopen, utan de kunde också användas av prästerskapet och menige man för att föra fram klagomål och önskningar till biskopen.[4] Detta skall jag emellertid inte gå in närmare på här. Låt oss istället se vilken sorts texter de protokoll är, som bevarats från biskopens visitationer i Växjö stift under 1650-talet.

\section{0-talets biskopsvisitationer som textsorter}

De källor som ligger till grund för vår rekonstruktion av 1600-talets biskopsvisitationer är de protokoll som nedtecknades av stiftsnotarien vid själva visitationsakten. Visitationerna inleddes vanligtvis med att gudstjänst förrättades var efter katekesförhör hölls med de närvarande församlingsborna. Närvaron vid visitationerna var obligatorisk och ingen fick lov att utebli utan laga förfall. Den som var frånvarande utan giltig orsak riskerade att bötfällas. Då katekesförhöret var över och de som visat sig duktiga berömts och de mindre framstående bannats, fick kvinnorna och de yngre lov att bege sig hemåt. Socknens män, det lokala prästerskapet samt biskopen och hans följe stannade kvar i kyrkan för att avhandla de frågor som ansågs viktiga.[5]

Som historiker utsätter man alltid det material som man önskar använda sig av för en källkritisk analys enligt fyra källkritiska kriterier. Man frågar efter äkthet, tidssamband, beroende och tendens.[6] Om man vill avgöra exakt vad som togs upp till behandling vid visitationerna, ställs man omedelbart inför ett stort problem. Allt som sades och gjordes vid visitationerna fördes inte till protokollet. Denna iakttagelse grundar sig på det faktum att det ibland står nedtecknat att en visitation hållits, men inte ett ord om vad som avhandlades vid denna.[7] Detta gör det i princip omöjligt att att exakt återge vilken typ av frågor som togs upp till behandling vid biskopsvisitationerna. Man måste därför ställa sig frågan, vad som fördes till protokollen och vad som utelämnades. Det intryck man får, är att det som nedtecknades var det som ansågs särskilt viktigt eller sådant som skulle åtgärdas eller tas upp till behandling vid ett senare tillfälle, t ex i domkapitlet eller vid tinget. De bevarade protokollen visar alltså inte vad som togs upp till behandling vid visitationerna utan snarare vad som ansågs vara viktigt att anteckna och bevara för framtida bruk. Det handlar inte om ett systematiskt uteslutande av olika ärendetyper från den kyrkliga överhetens sida, men man kan inte komma förbi det faktum att det var kyrkans män som avgjorde vad som var värt att föra till protokollet och inte. Detta är en problematik som man måste vara medveten om när man arbetar med ett material av denna typ.

Vad gäller de källkritiska aspekterna kan vi konstatera att protokollen nedtecknats av den stiftsnotarie som följde med biskopen på dennes visitationsresor runt om i stiftet. Han förde anteckningar under själva visitationsakten. Dessa renskrevs sedan. Jag har, då det varit möjligt, jämfört de renskrivna protokollen med "kladdarna" och då funnit att de inte skiljer sig åt på något anmärkningsvärt sätt. Notarien var med vid själva visitationen. Han var närvarande i samma rum och såg och hörde med egna ögon och öron vad som avhandlades. Av detta följer att vi inte har några källkritiska anmärkningar att rikta mot protokollen när det gäller tidssambandet eller beroendekriteriet.

Jag har tidigare berört problemet med vad som förts till protokollen och vad som utelämnats. Materialet är tillkommet på överhetens initiativ, och av detta följer att man är tvungen att iaktta en viss försiktighet, om man vill komma åt folkets röst i materialet. Det är överhetens tolkningar av vad som gjordes och sades som möter oss i protokollen. Jag har däremot svårt att tänka mig att materialet skulle vara tendensiöst, dvs vinklat eller tillrättalagt, i det avseendet att det skulle innehålla uppgifter som medvetet förvridits eller förvanskats i ett visst syfte. Varför skulle man medvetet föra in falska uppgifter i sitt eget arkiv? Jag utgår också från att materialet är äkta, då jag inte kan se någon anledning till varför någon skulle kunna ha något intresse av att förfalska denna typ av material.[8]

En text kan ha ett eller flera olika syften och syftet påverkar textens utseende. Syftet med en text är vanligtvis något av nedan nämnda punkter: Med texten önskar man: 
- Informera.

- Förmå någon att göra något.

- Övertyga.

- Lära ut.

- Skapa kontakt.[9]

Varför har protokollen nedtecknats och bevarats? Man måste komma ihåg att allt källmaterial tillkommit och bevarats för ett visst syfte. Protokollen från biskopsvisitationerna har nedtecknats och bevarats för att den information som protokollen innehåller skulle användas på ett eller annat sätt vid ett senare tillfälle. Protokollen skrevs i två exemplar. Ett skulle förvaras i domkapitlets eget arkiv, och ett protokoll skulle behållas i den visiterade församlingskyrkans arkiv. Uppgifter från visitationsprotokollen användes sedan vid sammanträden i domkapitlet, vid sammankomster vid tinget och då sockenstämmor hölls ute i de olika församlingarna om något behövde åtgärdas. De nedtecknade och bevarade protokollen gjorde att information som framkommit vid någon visitation kunde användas av personer som inte var närvarande vid det aktuella tillfället. Den skrivna informationen kunde t ex användas av biskopens eller den lokale prästmannens efterträdare, då en visitation hölls många år senare. Till viss del kan protokollen sägas vara offentliga, då hela eller delar av innehållet kunde läsas upp offentligt vid ting och sockenstämmor. Protokollen bör ha varit lätta att använda, då de ofta är lättöverskådliga och välskrivna med de olika ärendena indelade i olika punkter. Värt att nämna i sammanhanget är att notarien ibland gav språket lokalfärg då han skrev på dialekt. Ordet ofta kunde t ex ges den småländskt klingande stavningen öffte.[10]

Om man vill försöka att beskriva visitationernas funktion och syfte så kan man i första hand säga att de bevarades och nedtecknades på grund av att de innehöll information som ansågs vara viktig.

\section{Avslutning - Måns Haraldssons öde}

Hur gick det då för den Måns Haraldsson som vi mötte i inledningen? Efter den ovannämnda biskopsvisitationen är det tyst om Måns i nästan tio år, men vid nyårstid 1660 kom en skomakare vid namn Måns Haraldsson till Malmbäcks socken. Här bodde en kvinna vid namn Karin Persdotter, gift med en trumslagare som dragit ut i kriget och inte hörts av på mycket länge. Måns och Karin fattade tycke för varandra. Han var som vi sett redan gift, men han trodde inte att det skulle vara några svårigheter att få domkapitlet i Växjö att bevilja honom skilsmässa. Vid samma tid spreds också ett rykte i bygden som berättade att trumslagaren stupat. En dag upptäckte Karin att hon var med barn. Om Måns inte fick igenom sin skilsmässa och om trumslagaren inte var död, hade de begått dubbelt hor, ett brott som var belagt med dödsstraff. Måns och Karin bestämde sig för att rymma. För att få pengar till sin flykt sålde de trumslagarens kor, och genom en mindre nogräknad präst lyckades de skaffa sig förfalskade pass varpå de gav sig iväg. De slog sig ned i Östergötland, där Karin en tid senare födde deras barn. Allt var frid och fröjd tills den dag trumslagaren kom hem. Han lyckades spåra upp paret med hjälp av kronobetjäningen och Måns och Karin fördes till Jönköping för att rannsakas. Sommaren 1661 ställdes de inför rätta. Karin berättade att hon trott att trumslagaren var död och att skomakaren skulle få sin skilsmässsa beviljad när som helst. Måns sa att också han trott att mannen var död och att han skulle få lov att skiljas från sin hustru inom en snar framtid. Måns hustru var den Ingeborg Jonsdotter som vi mött vid visitationen i Malmbäck 1652. Deras förklaringar och ursäkter hjälpte föga och de dömdes till döden för dubbelt hor. Skomakaren skrev en supplik till hovrätten i vilken han berättade hur det egentligen stod till med hans äktenskap. Han berättade att han tvingats till vigseln med Ingeborg och att han under flera års tid försökt att få äktenskapet upplöst. Han hade vänt sig till såväl kyrkoherde och prost som till biskop och domkapitel för att få upprättelse men misslyckats. Han hoppades nu att Göta hovrätt skulle kunna hjälpa honom. Måns hoppades emellertid förgäves. Hovrätten dömde hårt och slog fast dödsdomarna. En höstdag i november 1661 avrättades Måns och Ingeborg för sin förbjudna kärlek.[11] 


\section{Sammanfattning}

1650-talets biskopsvisitationer ägde i regel rum en gång om året. De svenska biskoparna reste då runt i sina stift och försökte besöka så många församlingar som möjligt. Vid visitationerna togs en mängd olika ärenden upp till behandling. Visitationerna var främst till för att biskopen skulle kunna kontrollera sitt prästerskaps och sina församlingsbors religiösa tro och moraliska vandel. Vid visitationerna hade samtliga församlingsbor närvaroplikt. I min egen forskning sysslar jag med biskopsvisitationerna i Växjö stift under 1600- och 1700-talen och jag har vid ett flertal olika tillfällen varit tvungen att fundera över mitt källmaterials beskaffenhet. Många av de ärenden som togs upp till behandling vid visitationerna fördes till protokollet av den notarie som biskopen hade med sig vid sina visitationsresor. Allt fördes emellertid inte till protokollen utan endast sådant som ansågs vara viktigt eller som skulle åtgärdas vid ett senare tillfälle nedtecknades. Anledningen till att protokoll fördes och bevarades var alltså att den information som de innehöll skulle kunna användas vid ett senare tillfälle. Protokollen skrevs i två exemplar. Ett förvarades i domkapitlets eget arkiv och ett exemplar sparades i den visiterade församlingskyrkans eget arkiv. Uppgifter från protokollen användes sedan vid sammanträden i domkapitlet, vid tingsförhandlingar och vid sockenstämmor. Innehållet i visitationsprotokollen kan till viss del sägas vara offentligt då hela eller delar av protokollen kunde läsas upp offentligt. Protokollen var lätta att hämta uppgifter ur då de vanligen var lättöverskådliga och välskrivna med de olika ärendena indelade i punkter. Om man vill försöka förstå varför protokollen nedtecknades och bevarades så kan man säga att den främsta orsaken var att de innehöll information som betraktades som viktig.

\section{(Föredrag hållet vid Textsortsymposium på Högskolan i Växjö 960906)}

[1]Ärendet är hämtat från biskopsvisitationen i Malmbäck den 13 juli 1652. ValA, VDA, Protokoll från biskopsvisitationer 1652-84. FIIa:1.

[2] Om biskopsvisitationer se tex Olle Larsson, Biskopsvisitationer i Norra Allbo under 1600-talet. Värendsbygder. Norra Allbo Hembygdsförening 1996 sid 86-107.

[3]Then Swenske Kyrkeordningen. Läter all ting ährliga och skickeliga tillgå.1 Cor. 14. Tryckt j Stockholm aff Amund Laurentzon. Anno Domoni MDLXXI.

Petrus Jonae Angermannus, Cursus Visitationis Dioecesis Wexionensis. Uthi hwilkom huffvudgrunden aff the öffning medh Christi försambling I effter Catechismi ordning uthi visiteringen hållin/korteliga är författat/Lärarom och Åhörarom nyttig att öffuerläsa och begrunda. Item hustafflan/författat i sex predikningar/allom them som på ämbetes och tiänsts wegna ther uthi rum haffua/nödtorfftig att weta och öffuerwäga. Sammandragin och utgångin aff M PetroJonae Angermannus E.VV. Prentat i Rostock aff Christff Rensuer Anno MDVC.

[4] Se Olle Larsson, Biskopen visiterar. Biskopsvisitationernas verksamhet, aktörer och sanktioner i Växjö stift under 1650-talet. Opublicerat avhandlingsavsnitt vid Historiska Institutionen vid Lunds Universitet 1996.

[5] Det är ofta mycket svårt att fastställa vilka personer som var närvarande vid biskopsvisitationerna. Klara bestämmelser för närvaron vid visitationerna kommer först med 1686 års kyrkolag. Se Sveriges kyrkolag af år 1686.Utg. 1910 sid 272f.

[6]För en mycket översiktlig beskrivning av källkritikens grundläggande principer se Torsten Thurén, Orientering i källkritik. Är det verkligen sant? 1986.

[7]Se t ex biskopsvisitationen i Bolmsö den 5 novemder 1654. VaLA, VDA, Protokoll från biskopsvisitationer 1652-84. FIIa:1.

[8]För ett mer utförligt resonemang se Olle Larsson, Prästens Penningar och Berusade Bönder, Grälande Grannar och Tvivel i Tro. - Biskopsvisitationernas kompetensområde i en föränderlig tid 1650-1770. Opublicerat avhandlingsavsnitt vid Historiska Institutionen vid Lunds Universitet. 1995.

[9]Om textsorter se t ex Kurt Nyholm, Textsortsvarianten und Textsortenwandel am Beispiel des deutschen Briefs.

[10] Det tidigare nämnda protokollet från biskopsvisitationen i Malmbäck den 13 juli 1652 
Olle Larsson, 'Att använda biskopsvisitationsprotokoll som historisk källa'

innehåller exempel på dialektal stavning. VaLA, VDA, Protokoll från biskopsvisitationer 1652-1684. FIIa:1.

[11] Slutet på historien om Måns Haraldsson är hämtad från Rudolf Thunander, Förbjuden kärlek. Sexualbrott, kärleksmagi och kärleksbrev i 1600-talets Sverige. 1992. 